\title{
EFFICACY OF AIR DISINFECTION DEVICES IN CONTROLLING ATMOSPHERIC MICROFLORA IN ENCLOSED HEALTH CARE SETTINGS.
}

Ravi Kumar R, Jyothi E. K, Nanda Kumar B. S, Madhava Murthy M. R.

1. Professor \& Head, Department of Neuromicrobiology, NIMHANS, Bangalore.

2. PhD Scholar, Department of Neuromicrobiology, NIMHANS, Bangalore.

3. Associate Professor cum Epidemiologist, Department of Community Medicine, MSRMC.

4. Chief Executive Officer, Innova Technology Solutions Mysore Pvt Ltd., Bangalore.

\section{CORRESPONDING AUTHOR}

Dr. R. Ravi Kumar MD,

Professor and Head,

Department of Neuromicrobiology,

NIMHANS, Bangalore,

E-mail: ravikumarbly@yahoo.co.uk,

Ph: 00919448073965.

ABSTRACT: INTRODUCTION: There is increasing concern with the prevalence of hospital infection. This is causing a significant economic and logistical burden on the health services.

OBJECTIVES: To assess the efficacy of hydroxyl radical based air disinfection devices in reducing the atmospheric pathogen count in enclosed health care settings. MATERIALS AND METHODS: Sequential trial with repeated readings was designed before and after installation of the Air Disinfection devices. Study was conducted at 52 points in different locations which included sections from out Patient Department, Intensive Care Units, Operation Theatre, Surgical Ward, Radiology Department and cubicles in routine microbiology. The samples collected with air sampler were processed in Neuromicrobiology Laboratory. RESULT: It was observed that the mean $( \pm \mathrm{SE})$ colony forming units $\left(\mathrm{CFU} / \mathrm{m}^{3}\right)$ count after 24 and 48 hours before and after use of air disinfectant devices at the above locations were $159.75( \pm 35.42)$, $210.31( \pm 65.15)$ and $44.04( \pm 14.15), 55.31( \pm 15.06)$ respectively. The differences in the mean CFU concentrations were found to be statistically significant $(\mathrm{p}=0.006)$. Additionally, a high degree of variance in the CFU counts was noted before using the devices as compared to that after using the same. CONCLUSION: The results indicate that there is considerable reduction in the number of colony forming units subsequent to the introduction of the Air Disinfection devices. These devices supplement and compliment the general hygienic practices. However owing to a lot of compounding factors affecting the colony forming units in a given location, sufficient care must be taken for ascribing the reduction in the counts only to the device.

KEYWORDS: Air Disinfection, Environmental Flora, Disinfection Devices, Air Sampling, Hospital Infection.

INTRODUCTION: Hospitals and associated areas are high risk areas for acquiring infections ${ }^{1}$. Therefore, it is imperative that strict policies be implemented and maintained so as to achieve the goal of infection control. One of the modes to achieve the same is by air disinfection process wherein devices are used to reduce the number of microorganisms in the air. This concept in disease prevention is pivotal in certain high risk areas within the hospital like Intensive care units, operation theatres, and other sites where virulent and resistant organisms, high risk patients and invasive interventions are present. Prevention of infections by means of air disinfection will enhance and greatly synergise with other infection control measures and 
reduce the incidence of nosocomial infections(hospital acquired infections), suspected to arise by the air borne route.

There has been increasing concern with the prevalence of superbugs and hospital related infections in the past decade. Environmental dissemination of pathogens is an important issue associated with hospital and community acquired infections and therefore their control plays a vital role in the formulation of hospital infection surveillance system and antibiotic policies ${ }^{2}$. Different technologies are coming up for atmospheric disinfection which employs various principles for disinfection. The use of hydroxyl radicals is a very efficient mode of decontamination. The hydroxyl radical is a transient piece of energy. These radicals are highly reactive and consequently short lived. These are also called the detergent of the troposphere as these are often the first step to removal of pollutants. The attack process essentially leads to a cascade of reactions that may induce damage to nucleic acids, structural and functional changes in proteins, as well as oxidation of lipids. For example, lipids in a bacterial cell wall react with hydroxyl radicals by losing hydrogen and forming a lipid radical. Oxidation of proteins are far more complicated where a protein radical will lead many possible reactions, one of which resulting in a non-protein radical that can be a further hydroxyl radical ${ }^{3,4}$. In a microbial cell, due to interactions between proteins and lipids, the oxidative reactions can transfer from lipids to proteins and so on, causing destruction to main cellular structures which will render the bacteria non viable. Another study found that hydroxyl radicals are involved in cell killing by the bacterial Topoisomerase I Cleavage Complex ${ }^{5}$. The reactions between these hydroxyl radicals and bacteria are non-strain specific, therefore resistant and non-resistant bacterial strains will be equally susceptible to hydroxyl radicals' attack ${ }^{6}$.

The AD unit used in the study takes the surrounding air within an enclosed space, processes it and combines it with olefin - the natural scents of flowers and plants - creating hydroxyl radicals that react with the molecules in airborne pathogens and removes them 7,8 . Through this process the AD unit disinfects the air continuously.

OBJECTIVES: To assess the efficacy of hydroxyl radical based air disinfectant devices in reducing the atmospheric pathogen count in enclosed health care settings.

METHODOLOGY: Sequential air sampling before and after installation of air disinfectant devices were carried out. The air sampling device used was of the model LA030 Air Petri from Hi- Media. The volume of air sampled was $1,000 \mathrm{~L}\left(1 \mathrm{~m}^{3}\right)$. Time taken for sampling was 3 minutes with a flow rate of 300 litres/min. The machine uses a sieve impaction particle capture mechanism.

The sampled air was cultured on culture media namely sheep blood agar for bacterial isolation and Sabouraud's dextrose agar for fungal isolation. The plates were incubated at $37^{\circ} \mathrm{C}$ for 24-48 hours. First reading was taken after 24 hours of incubation, and the second reading after 48 hours of incubation. Quantitative evaluation of $\mathrm{CFU} / \mathrm{m}^{3}$ was performed by observing the culture and counting the colonies.

Study was conducted at 52 points in different locations of the hospital which included sections from outpatient department, intensive care units, operation theatre, surgical ward, radiology department and cubicles in the department of microbiology. Further processing was performed in the Neuromicrobiology laboratory as per standard guidelines. The air disinfectant device used was from Inov8 Air Disinfection Company, United Kingdom. Specific identification of the isolates was not performed during the study.

Journal of Evolution of Medical and Dental Sciences/Volume1/Issue5/November-2012Page-716 
STATISTICAL ANALYSIS: Continuous data were summarized by mean ( \pm SD) and Categorical data as proportions and percentages. Paired t-test was used to compare the statistical significance of differences in mean CFU counts before and after use of AD devices.

RESULTS: It was observed that the mean $( \pm$ SE) colony forming units (CFU)count after 24 and 48 hours before and after use of air disinfectant devices were $159.75( \pm 35.42), 210.31( \pm 65.15)$ and $44.04( \pm 14.15), 55.31( \pm 15.06)$ for Digital Subtraction Procedure centre, Neurology OPD, Neurosurgery OT and Spiral CT centre, respectively. Refer Table 1 to 4.

DISCUSSION:Pre AD CFU counts showed considerable variance and high counts viz a viz the post AD CFU counts. Subsequent to introduction of the AD device the counts reduced significantly.

The Hydroxyl radicals travel short distances and when it encounters oxidizable substrates this triggers a free radical cascade leading to cell injury at sites distant from where the initial free radical reaction occurred ${ }^{9}$. Previous studies ${ }^{10}$ show that the device significantly reduces the concentration of airborne microbes like S. epidermidis and MS-2 Coliphage by a factor of $5 \log 10$ within $1 \mathrm{hr}$. Independent tests have shown a kill rate of $99.999 \%$ in a typical space in less than 60 minutes. It has a slower effect on spores.

The air sampling showed a wide variation in the microbial counts in all the locations. The overall differences in the mean CFU concentrations were found to be statistically significant $(p=0.006)$. These devices supplement and compliment the general hygienic practices. However, owing to a lot of confounding factors affecting the colony forming units in a given location, sufficient care must be taken for ascribing the reduction in the counts only to the device.

The hydroxyl radical AD units may have a role in reducing the environmental burden of microorganisms in a high risk clinical setting. However, more data is required to demonstrate the efficacy of the system.

\section{ACKNOWLEDGEMENTS:}

The entire faculty, residents, technicians and other staff of Department of Neuromicrobiology, NIMHANS, Bangalore. All the staff of the Departments of Neurology, Neurosurgery, Neuroanaesthesia and Neuro Imaging and Interventional Radiology.

\section{REFERENCES:}

1. World Health Organization. Guidelines on Prevention and Control of Hospital Associated Infections. WHO, Geneva, 2002.

2. Wong V, Staniforth K, Boswell TC. Environmental contamination and airborne microbial counts: a role for hydroxyl radical disinfection units? J. Hosp. Infect. 2011;1-6.

3. Garrison WM. Reaction mechanisms in the radiolysis of peptides, polypeptides, and proteins. Chem Rev 1987;87:381-98

4. Singh J \& Thornton J M. Atlas of Protein Side-Chain Interactions, Vols. I \& II, 1992. IRL press, Oxford.

5. Liu IF, Annamalai T, Sutherland JH, Tse-Dinh YC. Hydroxyl radicals are involved in cell killing by the bacterial topoisomerase I cleavage complex. J. Bacteriol. 2001; 191:5315-19. 
6. Inov8 Air Disinfection Combats Antibiotic Resistant Bacteria. In . Air disinfection solutions: effective against antibiotic resistant microorganisms. Aug 2010.

7. W e s c h l e r CJ, S h i e l d s HS. Production of the hydroxyl radical in indoor air. Environ. Sci. Technol. 1996; 30:3250-58.

8. Donahue NM, Kroll JH, Anderson JG, Demerjian KL. Direct observation of OH production from the ozonolysis of olefins. Geophysical Research Letters, 1998; 25: 59-62.

9. Miller RA, Britigan BE. Role of oxidants in microbial pathophysiology. Clin Microbiol Rev 1997;10:1-18.

10.10 Ezbiri A, Elen R. Review of current evidence on the reduction of infection rates in NHS hospitals using the Inov8 AD (air disinfection) technology. Hospital Infection Society Conference; 2010: Liverpool, UK.

TABLE 1: CFU count after 24 and 48 hours before and after use of air disinfectant devices at location 1- Digital Subtraction Procedure centre.

\begin{tabular}{|c|c|c|c|c|c|}
\hline \multicolumn{6}{|c|}{ Location $=$ Digital Subtraction Procedure } \\
\hline & Status & $\mathbf{N}$ & Mean & $\begin{array}{l}\text { Std. } \\
\text { Deviation }\end{array}$ & Std. Error Mean \\
\hline \multirow{2}{*}{ 24_CFU } & $\begin{array}{l}\text { Without } \\
\text { AD }\end{array}$ & 4 & 66.25 & 55.13 & 27.57 \\
\hline & $\begin{array}{l}\text { With } \\
\text { AD }\end{array}$ & 16 & 50.94 & 123.32 & 30.83 \\
\hline \multirow{2}{*}{ 48_CFU } & $\begin{array}{l}\text { Without } \\
\text { AD }\end{array}$ & 8 & 70.62 & 66.63 & 23.56 \\
\hline & $\begin{array}{l}\text { With } \\
\text { AD }\end{array}$ & 16 & 58.75 & 122.37 & 30.59 \\
\hline a. Loca & ital Su & & $\overline{e d u}$ & 05 & \\
\hline
\end{tabular}

Journal of Evolution of Medical and Dental Sciences/Volume1/Issue5/November-2012Page-718 
TABLE 2: CFU count after 24 and 48 hours before and after use of air disinfectant devices at location 2- Neurology OPD

\begin{tabular}{|c|c|c|c|c|c|}
\hline Location & EURO O & & & & \\
\hline & Status & $\mathbf{N}$ & Mean & Std. Deviation & Std. Error Mean \\
\hline \multirow{2}{*}{ 24_CFU } & $\begin{array}{l}\text { Without } \\
\text { AD }\end{array}$ & 8 & 300.00 & 155.86 & 55.11 \\
\hline & $\begin{array}{l}\text { With } \\
\text { AD }\end{array}$ & 8 & 76.88 & 71.71 & 25.35 \\
\hline \multirow{2}{*}{ 48_CFU } & $\begin{array}{l}\text { Without } \\
\text { AD }\end{array}$ & 8 & 641.25 & 548.67 & 193.99 \\
\hline & $\begin{array}{l}\text { With } \\
\text { AD }\end{array}$ & 8 & 110.00 & 94.30 & 33.34 \\
\hline$\overline{\text { Locat }}$ & $\overline{\mathrm{URC}}$ & $\mathrm{D}$ & 05 & & \\
\hline
\end{tabular}

TABLE 3: CFU count after 24 and 48 hours before and after use of air disinfectant devices at location 3- Neurosurgery 0T.

\begin{tabular}{|l|c|c|c|l|l|}
\hline \multicolumn{2}{|l|}{ Location = NEURO OT } \\
\hline & Status & N & Mean & Std. & Std. Error Mean \\
\hline & Without & 4 & 93.75 & 89.57 & 44.79 \\
& AD & & & & \\
\hline
\end{tabular}

Journal of Evolution of Medical and Dental Sciences/Volume1/Issue5/November-2012Page-719 


\begin{tabular}{|l|l|l|l|l|l|}
\hline 24_CFU & With & 14 & 6.79 & 15.64 & 4.18 \\
& AD & & & \\
\hline \multirow{2}{*}{ 48_CFU } & Without & 8 & 62.50 & 75.02 & 26.53 \\
& AD & 14 & 8.93 & 15.21 & 4.07 \\
\cline { 2 - 6 } & With & & & \\
& AD & & & \\
\hline
\end{tabular}

TABLE 4: CFU count after 24 and 48 hours before and after use of air disinfectant devices at location 4- Spiral CT centre

\begin{tabular}{|c|c|c|c|c|c|}
\hline Location & RAL CT & & & & \\
\hline & Status & $\mathbf{N}$ & Mean & $\begin{array}{l}\text { Std. } \\
\text { Deviation }\end{array}$ & Std. Error Mean \\
\hline \multirow{2}{*}{ 24_CFU } & $\begin{array}{l}\text { Without } \\
\text { AD }\end{array}$ & 4 & 38.75 & 41.11 & 20.55 \\
\hline & With AD & 14 & 54.64 & 134.06 & 35.83 \\
\hline \multirow{2}{*}{ 48_CFU } & $\begin{array}{l}\text { Without } \\
\text { AD }\end{array}$ & 8 & 66.88 & 85.90 & 30.37 \\
\hline & With AD & 14 & 66.50 & 140.23 & 37.48 \\
\hline \multicolumn{6}{|c|}{ d. Location = SPIRAL CT, P>0.05 } \\
\hline
\end{tabular}




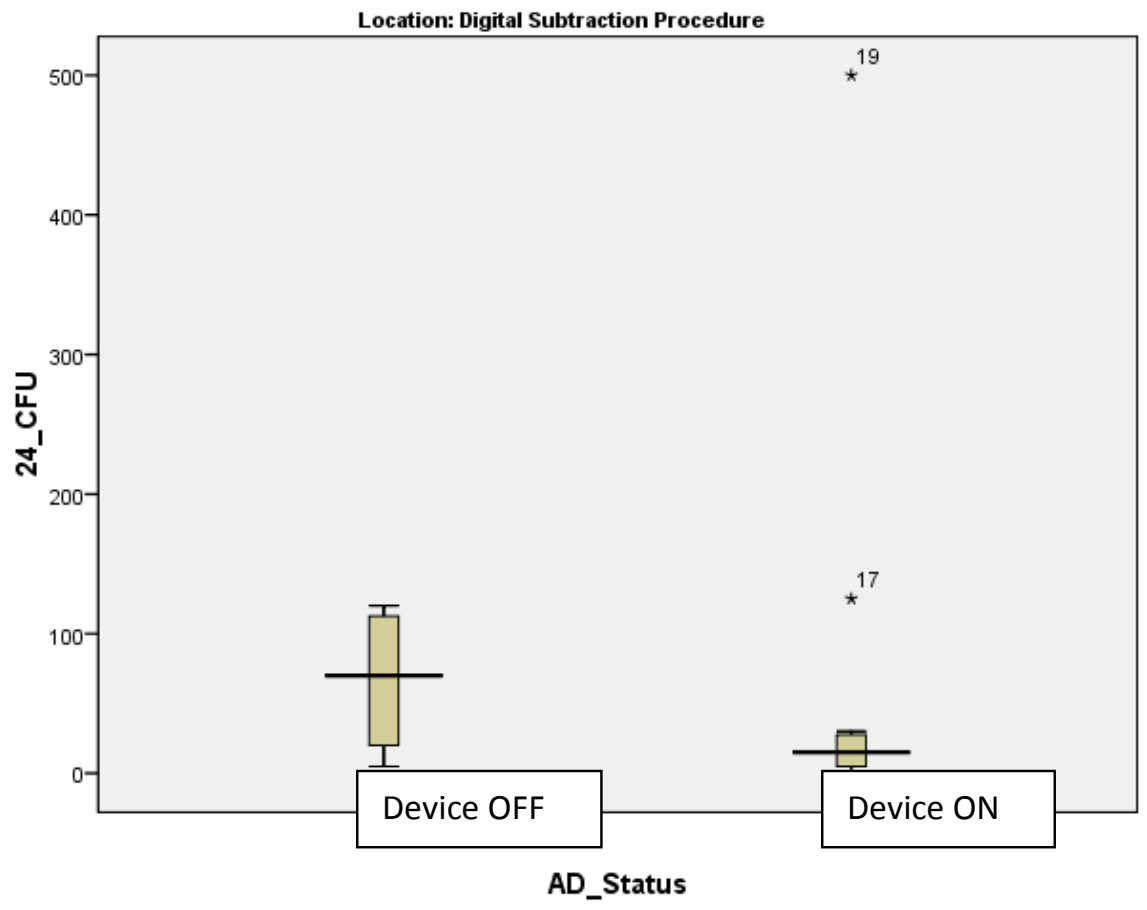

FIGURE 1: Box plot depicting the Mean (SD) CFU counts at DSP Room

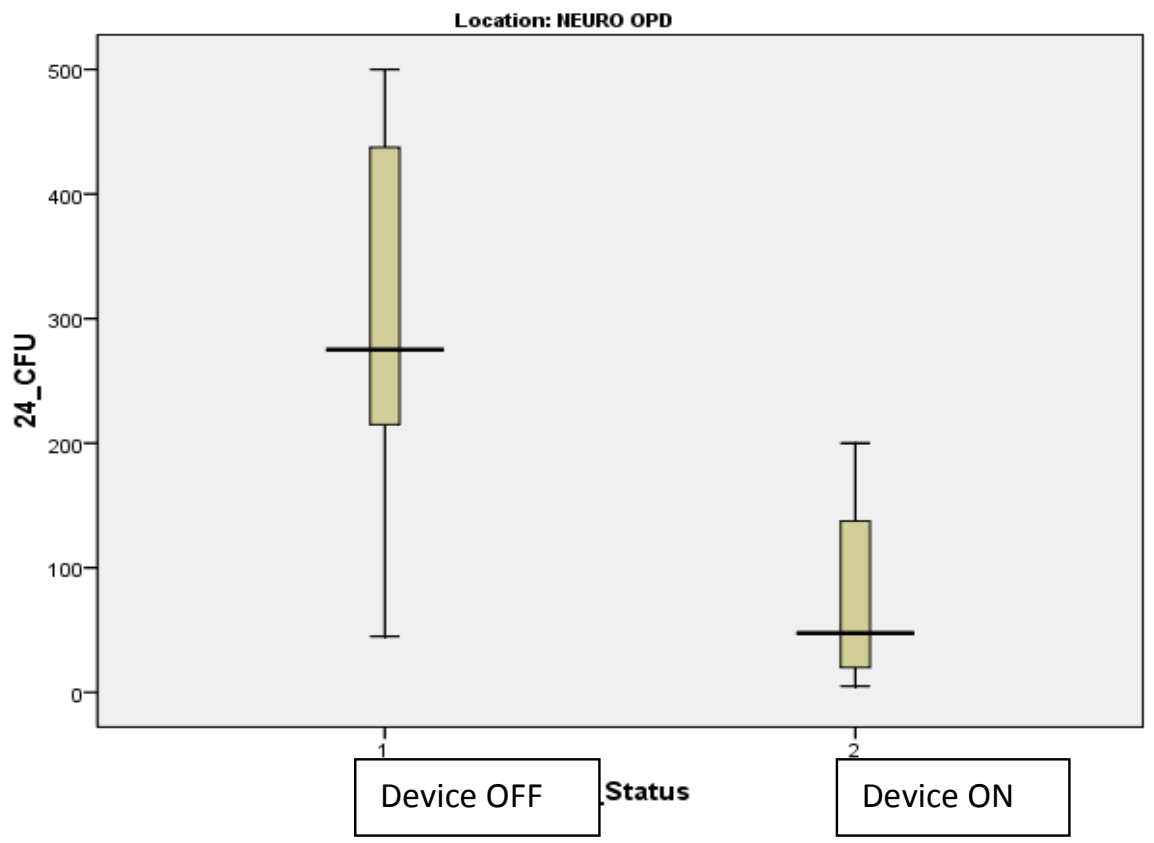

FIGURE 2: Box plot depicting the Mean (SD) CFU counts at Neuro OPD 


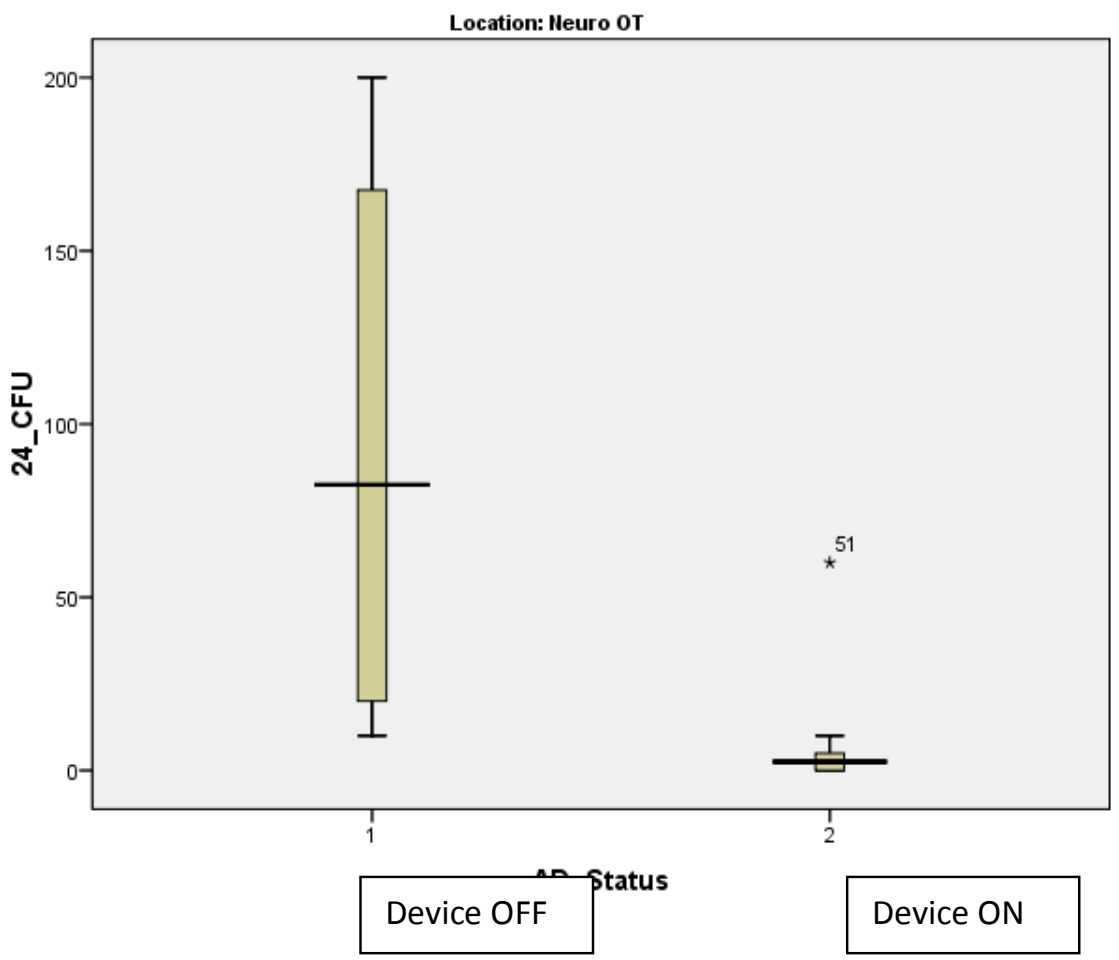

FIGURE 3 : Box plot depicting the Mean (SD) CFU counts at Neuro OT

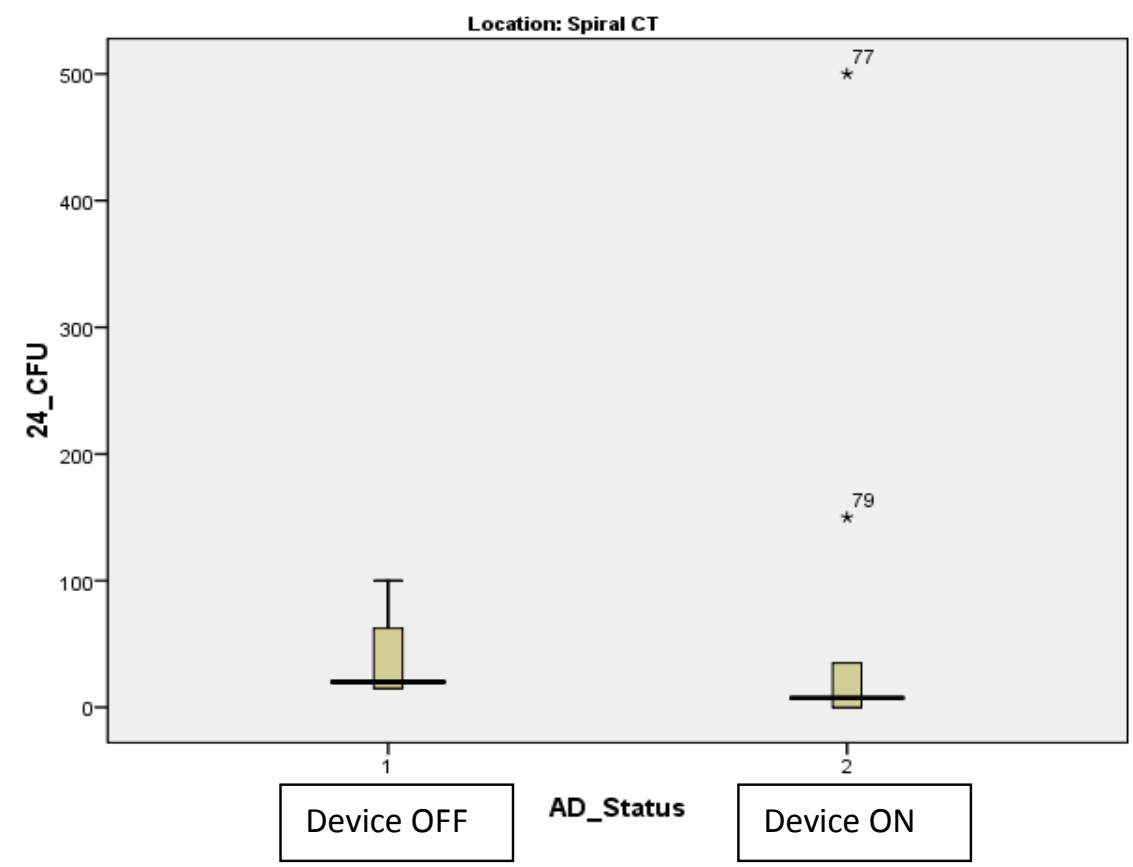

FIGURE 4: Box plot depicting the Mean (SD) CFU counts at Spiral CT center 